\title{
Calcium Levels Differences in Men with Schizophrenia Treated with Olanzapine and Risperidone in Prof. Dr. M Ildrem Psychiatric Hospital Medan
}

\author{
Starki Starki* (D), Bahagia Loebis, M. Surya Husada, N. Nazli Mahdinasari, Elmeida Effendy (D) \\ Department of Psychiatry, Faculty of Medicine, Universitas Sumatera Utara, Medan, Indonesia
}

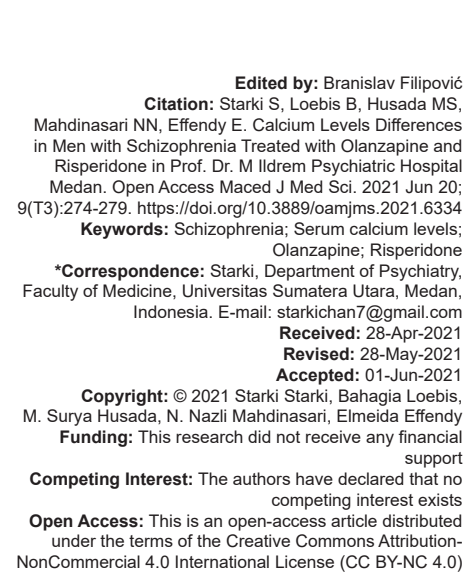

Introduction

Schizophrenia is a mental illness noticed by psychopathological damage that involves cognition, emotions, perceptions, behavioral aspects, and manifests in the patient and affects the course of the disease, which is usually severe and long-lasting. In addition, there are distortions of thought and perception that are fundamental and distinctive [1].

The simplest formulation of the dopamine hypothesis for the onset of schizophrenia is the result of excessive dopaminergic progressions, whereas high amount of dopamine release in people with schizophrenia has been correlated with the severity of positive symptoms of schizophrenia [2].

According to data from the Ministry of Health of the Republic of Indonesia, $90 \%$ of people with schizophrenia are the most mental disorders who experience shackling because research shows that the main reason for shackling in more than $90 \%$ of cases is because of schizophrenia symptoms such as impaired perception, thinking that causes violent behavior by people with the schizophrenia. If examined more deeply, family shackling is primarily intended to provide protection, both for sufferers and other people [3].

Calcium is a mineral in the body with $99 \%$ found in the teeth and bones, only $1 \%$ is found in serum. Calcium metabolism requires other nutrients such as protein, Vitamin D, and phosphorus. The formation and maintenance of bones occur during life, strong bones early in life, including at the age of children, will provide better bone density at a later age. Calcium diet arrangements and other nutritional collaboratives differ slightly around the world. Most sources of calcium come from food, but the main sources are milk and vegetables. Calcium enters the blood circulation by absorption of food in the intestines. Calcium can be lost from the body through the skin, sweat, and hair, but the main loss occurs through urine. The normal range for total calcium is around $8.4-10.2 \mathrm{mg} / \mathrm{dl}$. The range varies between laboratories depending on the measurement method [4].

Adequate calcium in the blood is very important for many vital functions of the body from the nerves, muscles, brain, and heart, the body will draw calcium 
from the bones, which are needed to maintain calcium levels in the blood if this cycle occurs continuously it will cause calcium reserves in the bones and teeth to be reduced [5].

In various literature, it is said that calcium is closely related to the regulation of neurotransmitters in the central nervous system. A process known to play a role in causing schizophrenia is to disrupt the neurotransmitter systems dopamine and glutamate. Calcium must be absorbed by the body every day and used effectively to maintain better health [6].

The N-methyl-D-aspartic acid (NMDA) receptor channel is blocked by magnesium at the resting membrane potential; thus, the NMDA receptors are silent until finally, the $\alpha$-amino- 3-hydroxy-5-methyl-4-isoxazole propionic acid (AMPA) receptor can depolarize neuron membranes to relieve magnesium blockade. The NMDA receptor requires the simultaneous binding of both ligands to two separate recognition sites for the channel to open, which forms a channel, which is a binding site called the glycine modulation site, where glycine and D- serine are endogenous ligands. The NMDA receptor requires the simultaneous binding of the sites of both ligands for the channel to open. The NMDA receptor serves as a chance detector because these events must occur simultaneously to open the channel when sufficient presynaptic glutamate has been released for the receptor, glycine, and D-serine are released, and the synaptic membrane depolarizes sufficiently to remove magnesium blockade. The NMDA receptor channels are large enough for calcium to pass easily. Calcium activates several kinases intracellularly, ultimately affecting the expression of the neuron gene. NMDA receptors are the most closely regulated neurotransmitter receptors. As described above, the two separate ligands must bind to two different subunits of the NMDA receptor function. The entry of calcium through NMDA receptors activates calmodulin, which in turn binds, reducing the frequency and duration of channel opening. Calcium binds to the ligand site of the Gamma-aminobutyric acid (GABA) sub-unit which functions to increase the affinity of GABA. Calcium deficiency can predispose to or one of the factors causing NMDA receptor hypofunction in schizophrenia [7].

Much of the literature reveals an association between antipsychotic drugs and decreased serum calcium levels, a recent review of sixteen studies investigating calcium in schizophrenic patients with the use of antipsychotics to be associated with osteoporosis. There is a small decrease in serum calcium from the short-term use of antipsychotics in schizophrenic patients, but over a long period, it will be clear that a significant decrease in serum calcium levels can have clinical consequences. As a result of the body is deficient in calcium, there is a decrease in the quality and quantity of bone composition resulting in bone loss. Several previous studies have described epidemiological evidence related to a decrease in the amount of calcium in the blood due to the use of antipsychotic drugs which causes low bone mineral density so that the quality and quantity of bone is impaired, this is seen from adolescents to the elderly population with various predisposing risks. Two disorders that increase the risk of fracture are osteoporosis (a state of impaired bone quality and quantity) and osteomalacia (a bone mineral depletion syndrome). Both bone disorders are important medical problems worldwide today and are one of the reasons why there is increasing interest in the medical community for various aspects of long-lasting bone mineral disorders, including chronic hypocalcemia. In addition to the osteoporosis process, the increased risk of fracture is well documented in treated patients with severe mental disorders. The decrease in calcium levels with antipsychotic therapy may be caused by several mechanisms, including the excretion mechanism in the kidneys, a condition where there is an increase in the excretion of calcium in the urine, and vice versa when there is low absorption of calcium [8]

In data obtained from Haishanwu and friends in 2012 in China, it is stated that antipsychotic drugs cause an increased risk of osteoporosis, this occurs because antipsychotic drugs are one that affects calcium absorption in the intestine. Antipsychotic drugs include pharmacological work to increase prolactin. Prolactin is a polypeptide hormone secreted by lactotroph cells in the anterior pituitary gland and inhibits the function of prolactin secretion. Inhibition of prolactin secretion occurs through binding to D2 receptors on the membrane of lactotroph cells and involves several signal transduction systems. Atypical antipsychotics such as risperidone, clozapine, and olanzapine are associated with elevated serum prolactin and influencing calcium concentrations. Increased prolactin is associated with calcium absorption in the intestine. The biomolecular underlying explanations for direct effects are not fully known. Prolactin increases in a prolonged manner can cause hypogonadism, resulting in affecting the secretion of gonadotropin-releasing hormone, luteinizing hormone, and follicle-stimulating hormone in the hypothalamus reduced by the pituitary gland, thus affecting the synthesis and absorption of calcium in the intestine [9].

\section{Methods}

This study is an experimental pre-test and post-test that compares two groups, namely the intervention group (olanzapine) and the control group (risperidone). Group I: A group of men with schizophrenia who received olanzapine therapy. Group II: A group of men with schizophrenia who received risperidone therapy. The sampling method was nonprobability sampling with a consecutive sampling 
type. The research was conducted at the inpatient installation of Prof. Dr. M. Ildrem Psychiatric Hospital Medan in June-July 2020. The study was conducted with 60 research subjects, namely 30 subjects who received olanzapine and 30 subjects who received risperidone. The inclusion criteria in this study were: Men with schizophrenia who met the PPDGJ-III criteria in Prof. Dr. M. Ildrem Psychiatric Hospital Medan North Sumatra, Schizophrenia in the acute phase, cooperative and willing as research subjects, aged 15-35 years, minimum junior high school education level, has a total PANSS score 90-150, normal body mass index, normal calcium levels $8.4-10.2 \mathrm{mg} / \mathrm{dl}$. The exclusion criteria in this study were in the healing phase such as fractures, history of other general medical illnesses, history of using psychoactive substances, taking multivitamins and minerals containing calcium, heart drugs, antibiotics and antacids, and heavy smoking.

\section{Procedures}

The procedure of this study used interviews in accordance with the diagnosis guidelines based on PPDGJ-III, then continued with screening using inclusion and exclusion criteria. The procedure of this study used interviews in accordance with the diagnosis guidelines based on PPDGJ-III, then continued with screening using inclusion and exclusion criteria. Patients who met the inclusion criteria were asked for consent to participate in the study after getting the approval of the family and the hospital director.

Blood samples were taken from male patients with schizophrenia before receiving olanzapine and risperidone treatment at the same hour, before activity, and before meals. Blood samples were taken through the median cubital vein as much as $3 \mathrm{~mL}$ and collected into a vacuum tube with lithium anticoagulant heparin spray. Then, the blood sample was immediately taken to the USU Hospital laboratory to measure the serum calcium level.

Then, the patient is given a flexible dose of olanzapine given starting from a dose of $10 \mathrm{mg}$ at night, then the PANSS score pre-treatment and will be measured every following week, if the PANSS score has not reached the response, the olanzapine dose will be added by $5 \mathrm{mg} /$ week and so on until a response occurs, maximum dose of $20 \mathrm{mg}$. Moreover, the other group was given a flexible dose of risperidone starting from $4 \mathrm{mg}$ in divided doses in the morning and evening, then the PANSS score was measured in the following week, if the PANSS score had not reached the response, the risperidone dose would be added by $1 \mathrm{mg}$ then the PANSS score was measured again and so on. up to a maximum dose of $8 \mathrm{mg}$ at the end of the $4^{\text {th }}$ week the serum calcium levels of the subjects in this study were re-measured. If the research subject drops out due to discontinuation of treatment or side effects, and on treatment, analysis will be carried out on the research subject.
After all of the blood samples and the subject's data were filled, the blood samples were collected then processed and analyzed the data. This study has received approval from the Research Ethics Committee at the Faculty of Medicine, University of North Sumatra, Medan.

\section{Statistical analysis}

The analysis test was performed on the variable serum calcium levels of men with schizophrenia who received olanzapine and risperidone therapy. The data normality test was carried out using the Shapiro-Wilk test because the sample in this study was 30 subjects (less than 51). If the data were normally distributed, we followed by an unpaired t-test on serum calcium levels at the end of week 4 between the groups receiving olanzapine and risperidone. However, on the contrary, if it is not normally distributed, an attempt will be made to normalize the data by transforming the data with $\log 10$, and if the attempt to normalize the data is unsuccessful, a Mann-Whitney $U$ test will be performed. The serum calcium level value of men with schizophrenia who received olanzapine and risperidone displayed in the form of mean and standard deviation if normally distributed and if not normally distributed, then the data will be presented with the median (minimum-maximum). The serum calcium level at the beginning of week 0 , at the end of week 4 , if the data were normally distributed, we followed by a paired t-test. However, on the other hand, if it is not normally distributed, an effort will be made to normalize the data by transforming the data with log10, and if the effort to normalize the data is unsuccessful, the Wilcoxon test will be carried out. The difference in serum calcium levels of men with schizophrenia receiving olanzapine and risperidone will be determined by the $p$-value.

\section{Results}

The characteristics of the subjects of this study can be seen in Table 1 that the mean and standard deviation for the age of men with schizophrenia in the group receiving olanzapine therapy were $25.63 \pm 4.74$, while the mean and standard deviation for the age of men with schizophrenia in the group who received risperidone $26.70 \pm 4.44$ obtained $p=0.37$ (The age level of the two groups of research subjects was not significantly different).

\section{Demographic characteristics of research subjects}

Table 1 shows demographic characteristics of our samples (age, education status, occupation, nuptial status, BMI, social-economic status, baseline calcium level, and baseline PANSS score) which did 
Table 1: Sample distribution based on demographic characteristics

\begin{tabular}{|c|c|c|c|}
\hline \multicolumn{2}{|c|}{$\begin{array}{l}\text { Male with schizophrenia who are receiving } \\
\text { Olanzapine }(n=30)\end{array}$} & \multirow[t]{2}{*}{$\begin{array}{l}\text { Men with schizophrenia } \\
\text { who are receiving } \\
\text { risperidone }(n=30)\end{array}$} & p-value \\
\hline \multicolumn{3}{|l|}{ Age (year) } & \\
\hline Mean \pm s.d & $25.63 \pm 4.74$ & $26.70 \pm 4.44$ & $0.37^{\mathrm{a}}$ \\
\hline \multicolumn{4}{|l|}{ Education level } \\
\hline Junior High School & $15(50.0 \%)$ & $18(60.0 \%)$ & \multirow[t]{3}{*}{$0.44^{b}$} \\
\hline Senior High School & $11(36.7 \%)$ & $9(30.0 \%)$ & \\
\hline University & $4(13.3 \%)$ & $3(10.0 \%)$ & \\
\hline \multicolumn{4}{|l|}{ Occupational status } \\
\hline Employed & $13(43.3 \%)$ & $11(36.7 \%)$ & \multirow[t]{2}{*}{$0.79^{\circ}$} \\
\hline Unemployed & $17(56.7 \%)$ & $19(63.3 \%)$ & \\
\hline \multicolumn{4}{|l|}{ Marital status } \\
\hline Married & $8(26.7 \%)$ & $10(33.3 \%)$ & \multirow[t]{2}{*}{$0.78^{\mathrm{c}}$} \\
\hline Unmarried & $22(73.3 \%)$ & $20(66.7 \%)$ & \\
\hline \multicolumn{4}{|l|}{ BMI $\left(\mathrm{kg} / \mathrm{m}^{2}\right)$} \\
\hline Mean \pm s.d & $21.89 \pm 1.78$ & $21.69 \pm 1.30$ & $0.62^{\mathrm{a}}$ \\
\hline \multicolumn{4}{|l|}{ Socioeconomic level } \\
\hline Low class & $16(53.3 \%)$ & $17(56.7 \%)$ & \multirow[t]{3}{*}{$0.75^{\mathrm{b}}$} \\
\hline Middle class & $9(30.0 \%)$ & $9(30.0 \%)$ & \\
\hline High class & $5(16.7 \%)$ & $4(13.3 \%)$ & \\
\hline \multicolumn{4}{|c|}{ Initial calcium serum level (mg/dl) } \\
\hline Mean \pm s.d & $9.12 \pm 0.50$ & $9.23 \pm 0.48$ & $0.42^{\mathrm{a}}$ \\
\hline \multicolumn{4}{|l|}{ Initial PANSS (score) } \\
\hline Mean \pm s.d & $108.07 \pm 10.08$ & $110.03 \pm 10.62$ & $0.47^{\mathrm{a}}$ \\
\hline
\end{tabular}

not indicate any significant difference in between the intervention group (receiving olanzapine) and control group (receiving risperidone).

Table 2, it was shown that the two groups who received olanzapine and risperidone at the end of week 4 with a value of $p=0.023$ where there was a significant difference in serum calcium levels of men with schizophrenia between the group that received olanzapine and the group that received risperidone at the end of week 4.

Table 2: Serum calcium levels post-treatment between schizophrenic men receiving olanzapine and risperidone therapy at the end of week 4

\begin{tabular}{llll}
\hline Parameters & Mean \pm s.d & p-value & Mean differences $(\mathrm{Cl} \mathrm{95 \% )}$ \\
\hline Final serum calcium level 4 & $7.803 \pm 0.508$ & 0.023 & $0.317(0.046-0.588)$ \\
week with Olanzapine $(n=30)$ & & & \\
$\begin{array}{l}\text { Final serum calcium level } 4^{\text {th }} \\
\text { week with risperidone }(n=30)\end{array}$ & $7.487 \pm 0.541$ & & \\
\hline
\end{tabular}

Table 3 showed a very significant difference in serum calcium levels of men with schizophrenia who received olanzapine therapy and men with schizophrenia who received risperidone therapy at the beginning of week 0 to the end of week 4 with $p<0.001$.

Table 3: Table of differences in serum calcium levels between schizophrenic men receiving olanzapine therapy and men with schizophrenia who received risperidone therapy at the beginning of week 0 to the end of week 4

\begin{tabular}{llll}
\hline Parameters & Group & $\begin{array}{l}\text { Median } \\
\text { Minimum-Maximum }\end{array}$ & p-value \\
\hline The difference between in serum & Olanzapine & $(1.40)$ & $<0.001$ \\
calcium levels at the beginning of & Risperidone & $(0.8)-(1.6)$ & \\
week 0 and the end of $4^{\text {th }}$ week & & $(1.70)$ & \\
& & $(1.3)-(2.3)$ & \\
\hline
\end{tabular}

Graph 1 shows the PANSS score in the two groups of study subjects who received olanzapine treatment and who received risperidone showed almost the same graph and showed a decrease in the PANSS score in both groups so that it can be said that each group in this study found treatment progress based on the PANSS score.

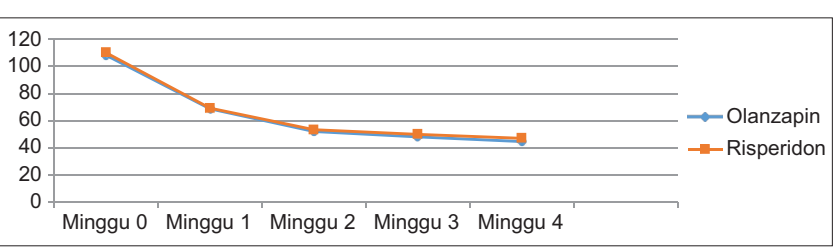

Graph 1: Observation of the mean PANSS score in the two groups of subjects who received olanzapine and risperidone treatment from the initial week to week 4

Graph 2 shows the mean dose equivalent of olanzapine to risperidone and dose of risperidone during three weeks of treatment, it is seen that the equivalence of the equivalence between the two drug groups can be found in the initial week to $4^{\text {th }}$ week.

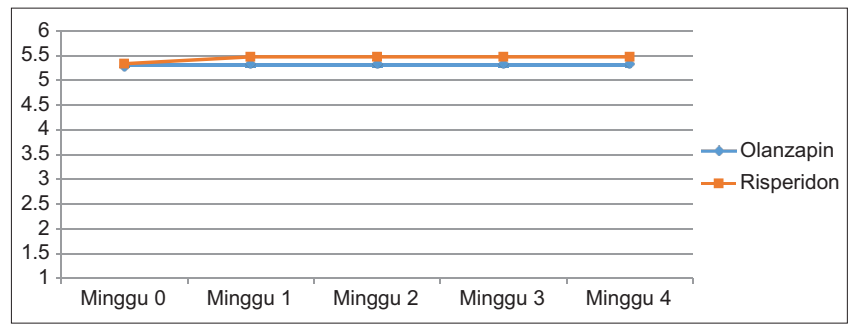

Graph 2: Observations mean dose in the two groups of men with schizophrenia who received olanzapine and risperidone treatment from the initial week to week 4

\section{Discussion}

This study is an on-treatment analysis and is an experimental study comparing two groups, namely the group receiving olanzapine and the group receiving risperidone to determine the difference in serum calcium levels in men with schizophrenia between the group receiving olanzapine and the group receiving risperidone in an inpatient installation. Prof. Mental Hospital. dr. M. Ildrem Medan in the period from June 2020 to July 2020 . The subjects were 30 people for the group that received olanzapine and 30 people in the group that received risperidone.

This study only included male sex because based on the study of Pravina et al. in India in 2012 related to gender, it was said that in women's serum calcium levels can be influenced by several things such as menstruation, menopause, pregnancy, and breastfeeding.

Both groups of subjects, both in men with schizophrenia who received olanzapine treatment and subjects in men with schizophrenia who received treatment of risperidone, were given a flexible-dose by first using an equivalent dose of olanzapine and risperidone.

Calcium plays an important role in the regulation of neurotransmitters in the central nervous system. The main process is modulated by calcium in causing 
changes to the dopamine and the neurotransmitter glutamate system in schizophrenia. The dopamine hypothesis represents hyperactivity of dopaminergic transmission while the glutamate hypothesis postulates the hypofunction of the NMDA receptor. Calcium includes NMDA permeable glutamate receptors deregulation of intracellular calcium homeostasis and signaling involved in the pathogenesis of schizophrenia [10].

The mechanism that occurs is that antipsychotic drugs block dopamine D2 receptors from lactotrophs in the anterior pituitary gland and affect the secretion function of prolactin; prolactin secretion occurs through binding to $\mathrm{D} 2$ receptors on the lactotroph cell membrane and involves multiple signal transduction systems. Increased prolactin affects the calcium concentration which is associated with calcium absorption in the intestine. The molecular mechanisms for direct effects are not fully understood [9].

In this study, there was a difference in the decrease in the amount of serum calcium after the administration of olanzapine and risperidone for 4 weeks, where risperidone decreased serum calcium levels more than olanzapine. This may be due to differences in the affinities of the two drugs [11].

This result is in line with another study conducted by Lee et al. in 2010 in South Korea, which also investigated factors related to bone metabolism, including plasma calcium level between those receiving $1 \mathrm{mg}$ risperidone and $2.5 \mathrm{mg}$ of olanzapine. They found a significant decrease of bone density in schizophrenic patients prescribed with risperidone and olanzapine $(p<0.05)$, which is correlated to baseline calcium level [8].

Another study from Milovanovic et al. in Serbia in 2010 also indicated a similar result in which patients receiving risperidone are more frequently suffered from hypocalcemia ( $p<0.001$ ) and that average plasma calcium level is significantly lower in risperidone group regardless of diagnosis and risk of electrolyte imbalance [6].

The advantage of this study is to measure the serum calcium level where the serum calcium level is considered more sensitive than the calcium level in urine to reflect intracellular calcium status.

The limitation of this study is that this study also did not see a decrease in serum calcium levels every week, to see when a significant decrease in serum calcium levels began after the administration of olanzapine and risperidone.

\section{Conclusion}

There was a difference in the initial serum calcium level in the olanzapine group with a mean of $9.12 \pm 0.50$ and a mean serum calcium level in the $4^{\text {th }}$ week of $7.80 \pm 0.51$. It showed that there was a very significant difference in serum calcium levels of men with schizophrenia who received olanzapine therapy at week 0 and week 4 with a value of $p<0.001$.

There was a difference in the initial serum calcium level in the risperidone group with a mean of $9.23 \pm 0.48$ and a mean serum calcium level for week 4 of $7.49 \pm 0.54$. It showed that there was a very significant difference in serum calcium levels of men with schizophrenia who received risperidone therapy at week 0 and week 4 with a value of $p<0.001$.

There was a significant difference in serum calcium levels of men with schizophrenia who received olanzapine and risperidone at the end of week 4 with a value of $p=0.023$, with a mean of $7.80 \pm 0.51$ for serum calcium levels in men with schizophrenia in the group received olanzapine at the end of the $4^{\text {th }}$ week, while the mean of the risperidone group at the end of the $4^{\text {th }}$ week was $7.49 \pm 0.54$, where there was a lower decrease in the risperidone group.

\section{References}

1. Lee TY, Chung MY, Chung HK, Choi JH, Kim TY, So HS. Bone density in chronic schizoprenia with long term antipsychotic treatment: Preliminary study. Psychiatry Investig. 2010;7(4):278-84. https://doi.org/10.4306/pi.2010.7.4.278 PMid:21253412

2. Stahl SM. Psychosis and schizophrenia. In: Stahl's Essentia Psychopharmacology: Neuroscientific Basis and Practical Application. $4^{\text {th }}$ ed. Cambridge: Cambridge University Press; 2013. p. 155-237.

3. Beto JA. The role of calcium in human aging. Clin Nutr Res. 2015;4(1):1-8.

PMid:25713787

4. Siyam F, Klachko D. What is hypocalcemia? The importance of fasting samples. Cardiorenal Med. 2013;3(4):232-8. https://doi. org/10.1159/000355526

PMid:24474951

5. Pravina P, Sayaji G, Avinash G. Calcium and its Role in Human Body. India, Satara: Institute of Science; 2012. p. 1-11.

6. Ruljancic N, Mihanovic M, Cepelak I, Bakliza A. Platelet and serum calcium and magnesium concentration in suicidal and non-suicidal schizophrenic patients. Psychiatry Clin Neurosci. 2013;67(3):154-9. https://doi.org/10.1111/pcn.12038 PMid:23581866

7. Kane JM, Correl CU. Schizophrenia: Amino acid neurotransmitters. In: Sadock BJ, Sadock VA, Ruiz P, editors. Kaplan and Sadock's Comprehensive Textbook of Psychiatry. $10^{\text {th }}$ ed., Vol. 1. Philadelphia, PA: Lippincott Williams and Wilkins; 2017. p. 291-311.

8. Milovanovic D, Pirkovic MS, Simonovic S, Matovic M, Dejanovic SD, Jankovic SM, et al. Parameter of calcium metabolism fluctuated during initiation or changing of antipsychotic drugs. Psychiatry Investig. 2016;13(1):89-101. https://doi.org/10.4306/pi.2016.13.1.89

PMid:26766951 
9. Dahlan MS, editor. Besar Sampel dan Cara Pengambilan Sampel dalam Penelitian Kedokteran dan Kesehatan. Jakarta: Salemba Medika; 2010.

10. Stahl SM. Essential Psychopharmacology Prescriber's Guide. $5^{\text {th }}$ ed. Cambridge: Cambridge University Press; 2015. p. $485-602$.

11. Iriondo MR, Salaberria K, Echeburua E. Schizophrenia: Analysis and psychological treatment according to the clinical staging. Actas Esp Psiquiatr. 2013;41(1):52- 9.

PMid:23440536 